\title{
Nontraumatic Splenic Rupture
}

Nana Sefa, MD, MPH; Ananda V. Pandurangadu, MD; Amanda Mann, MD; Amit Bahl, MD, MPH

\section{A 25-year-old man presented for evaluation of lightheadedness as well as pain in his left shoulder, epigastric region, and right flank.}

\section{Case}

A 25-year-old college student presented to the ED following a near-syncopal episode. The patient stated he had felt lightheaded and had fallen to his knees immediately after taking a shower earlier that morning, but did not experience any loss of consciousness or injury. He denied a history of syncope or any recent trauma or fatigue. A review of the patient's systems was negative. His medical history was remarkable for irritable bowel syndrome; he had no surgical history. Regarding his social history, he admitted to occasional alcohol use but denied any tobacco or illicit drug use. He was not on any current prescription or over-the-counter medications and denied any allergies.

The patient's initial vital signs at presentation were: blood pressure, 112/58 mm $\mathrm{Hg}$; heart rate, 86 beats/min; temperature, $97.9^{\circ} \mathrm{F}$; and respiratory rate, 18 breaths/ min. Oxygen saturation was $100 \%$ on room air. The patient reported pain in his left shoulder, epigastric region, and right flank. He rated his pain as a "4" on a 0-to10 pain scale.

On physical examination, the patient was alert and oriented; he was thin and had mild pallor. His head, eyes, ears, nose, and throat; cardiac; pulmonary; and neurological examinations were normal. The abdominal examination revealed a soft, minimally tender epigastrium but with normal bowel sounds. Initial laboratory studies were remarkable for low hemoglobin (Hgb; $12.0 \mathrm{~g} / \mathrm{dL}$ ) and elevated aspartate transaminase (105 U/L), alanine aminotransferase (168 U/L), total bilirubin $(1.6 \mathrm{mg} / \mathrm{dL})$, and glucose $(179 \mathrm{mg} /$ $\mathrm{dL})$ levels. The patient's troponin I and lipase levels were within normal range. An electrocardiogram was unremarkable.

Given the patient's elevated hepatic enzymes, right upper quadrant ultrasound was obtained, which demonstrated a normal gallbladder, a moderate amount of complicated free fluid (with hyper-echoic densities suggestive of coagulated blood) in all four quadrants, and splenomegaly measuring $13.7 \mathrm{~cm}$ (Figure 1a and 1b). Based on the ultrasound findings, an abdominal and pelvic computed tomography (CT) scan with intravenous (IV) contrast was immediately obtained, which revealed free fluid, a sentinel clot sign around the enlarged spleen measuring $15 \mathrm{~cm}$, and a posterior splenic laceration measuring $1 \mathrm{~cm}$ (Figure 2).

Dr Sefa is a resident, department of emergency medicine, Beaumont Health System, Royal Oak, Michigan. Dr Pandurangadu is an assistant professor, department of emergency medicine, Rush University, Chicago, Illinois. Dr Mann is a resident, department of emergency medicine, Henry Ford Hospital, Detroit, Michigan. Dr Bahl is a director of emergency ultrasound and ultrasound fellowship director, department of emergency medicine, Beaumont Health System, Royal Oak, Michigan.

Authors' Disclosure Statement: The authors report no actual or potential conflict of interest in relation to this article. 

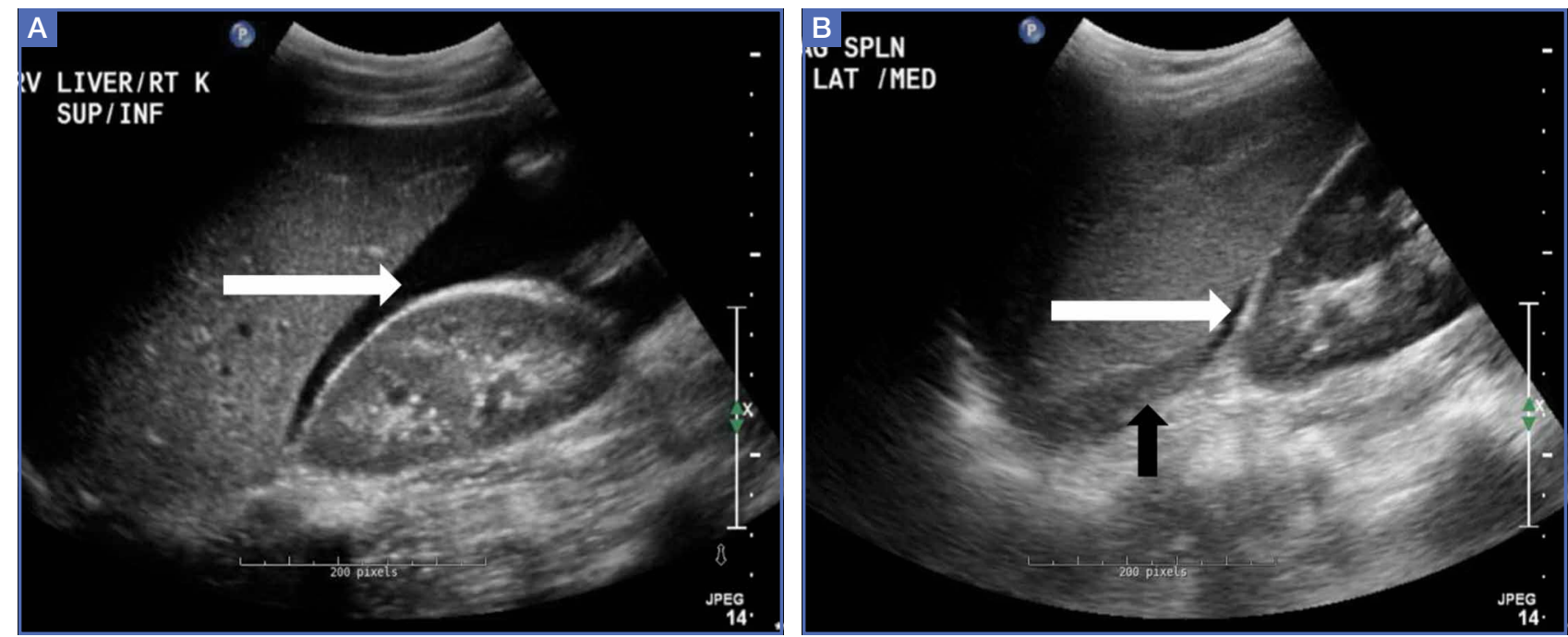

Figure 1. (A) Ultrasound of the patient's right upper quadrant demonstrating free fluid in Morrison's pouch (white arrow). (B) Ultrasound of the patient's left upper quadrant demonstrating splenic hematoma (black arrow) and free fluid in the splenorenal recess (white arrow).

The patient's status, including his vital signs, remained stable throughout his entire ED course. However, repeat laboratory studies taken 4 hours after initial evaluation revealed a further decrease of $\mathrm{Hgb}$ to $8.6 \mathrm{~g} / \mathrm{dL}$, for which the patient was given IV fluids and $2 \mathrm{U}$ of packed red blood cells. He was admitted to the intensive care unit, where he continued to be managed nonoperatively. Over the next 2 days the patient remained stable and his Hgb trended up. Additional laboratory testing prior to discharge revealed the following results:

\section{Positive:}

- Epstein-Barr virus (EBV)

- Viral capsid antigen (VCA) immunoglobulin G

n VCA immunoglobulin M

Negative:

- Mononuclear spot test

- Human immunodeficiency virus

- Hepatitis B and C

- Antinuclear antibodies

- Venereal disease research laboratory test

The rest of the patient's recovery was uneventful, and he was discharged home in stable condition on hospital day 3.

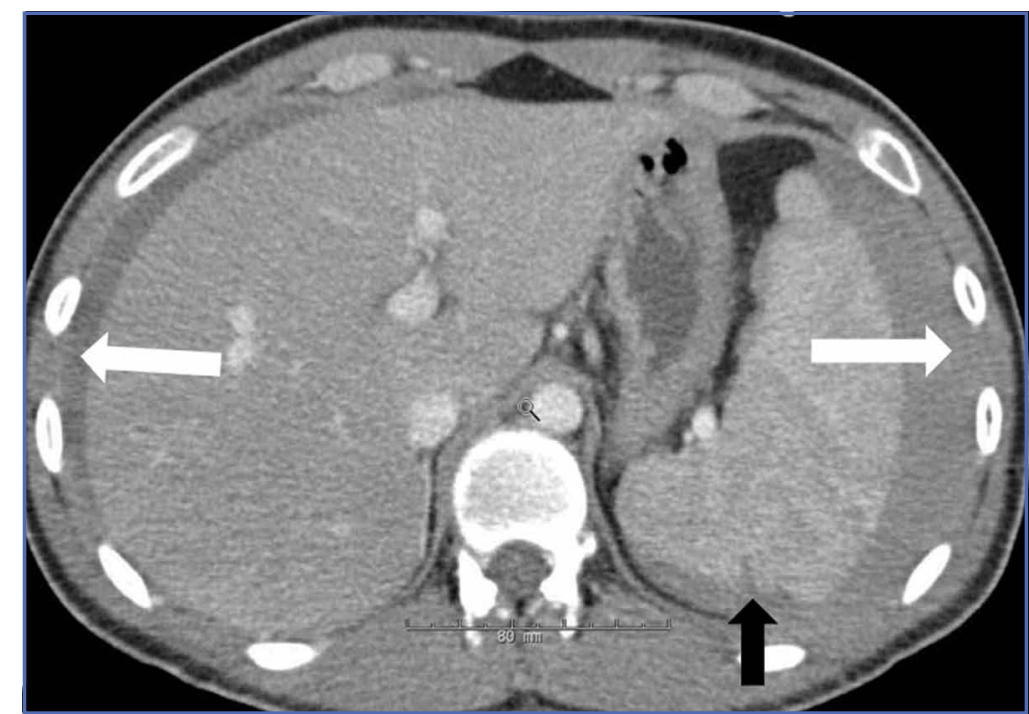

Figure 2. Computed tomography of the patient's abdomen demonstrating splenic laceration (black arrow) and free fluid in abdomen (white arrows).

\section{Discussion}

Although the spleen is the most common intra-abdominal organ that can rupture with blunt abdominal trauma, splenic rupture in the absence of trauma is very rare. Nontraumatic splenic rupture (NSR) has been associated with pathological and nonpathological spleens. ${ }^{1,2}$ A systemic review of NSRs showed that $7 \%$ of the 845 
Table. Classification of Splenic Laceration Injury ${ }^{11}$

\begin{tabular}{|c|c|c|}
\hline Grade & Injury Type & Injury Description \\
\hline \multirow[t]{2}{*}{1} & Hematoma & $\begin{array}{l}\text { Subcapsular tear, nonexpanding, <10\% } \\
\text { surface area }\end{array}$ \\
\hline & Laceration & $\begin{array}{l}\text { Capsular tear, nonbleeding, }<1 \mathrm{~cm} \\
\text { parenchymal depth }\end{array}$ \\
\hline \multirow[t]{3}{*}{2} & Hematoma & $\begin{array}{l}\text { Subcapsular tear, nonexpanding, } 10 \%-50 \% \\
\text { surface area }\end{array}$ \\
\hline & & $\begin{array}{l}\text { Intraparenchymal, nonexpanding, }<5 \mathrm{~cm} \\
\text { diameter }\end{array}$ \\
\hline & Laceration & $\begin{array}{l}\text { Capsular tear, active bleeding, } 1-3 \mathrm{~cm} \\
\text { parenchymal depth not involving a trabecular } \\
\text { vessel }\end{array}$ \\
\hline \multirow[t]{4}{*}{3} & Hematoma & $\begin{array}{l}\text { Subcapsular tear, }>50 \% \text { surface area or } \\
\text { expanding }\end{array}$ \\
\hline & & Ruptured subcapsular tear, active bleeding \\
\hline & & $\begin{array}{l}\text { Intraparenchymal hematoma, }>5 \mathrm{~cm} \\
\text { or expanding }\end{array}$ \\
\hline & Laceration & $\begin{array}{l}>3 \mathrm{~cm} \text { parenchymal depth or involving } \\
\text { trabecular vessels }\end{array}$ \\
\hline \multirow[t]{2}{*}{4} & Hematoma & $\begin{array}{l}\text { Ruptured intraparenchymal hematoma, } \\
\text { active bleeding }\end{array}$ \\
\hline & Laceration & $\begin{array}{l}\text { Laceration of segmental or hilar vessels } \\
\text { producing major devascularization } \\
\text { ( }>25 \% \text { of spleen) }\end{array}$ \\
\hline \multirow[t]{2}{*}{5} & Laceration & Completely shattered spleen \\
\hline & Vascular & $\begin{array}{l}\text { Hilar vascular injury that has } \\
\text { devascularized spleen }\end{array}$ \\
\hline
\end{tabular}

patients in the review had completely normal spleens; the remaining $93 \%$ had some form of splenic pathology. ${ }^{1}$

\section{Etiology}

The top three causes of splenic enlargement associated with NSR include hematologic malignancies, viral infections, and inflammation. ${ }^{1,2}$ Although viruses, such as EBV and cytomegalovirus, represent almost $15 \%$ of the pathological causes of NSR, it is not uncommon for a patient to have multiple pathological processes present. ${ }^{1}$ Our patient's enlarged spleen was due to acute infectious mononucleosis.

\section{Signs and Symptoms}

Diagnosing NSR can be challenging and it is often missed or discovered incidentally during evaluation (as was initially the case with our patient). ${ }^{3}$ Several signs and symptoms present in our patient were red herrings that warranted closer analysis. The patient's complaint of left shoulder pain suggested left hemidiaphragm irritation from the NSR. Furthermore, our patient's near-syncopal episode was possibly due to acute vagal simulation from the initial contact of blood with the peritoneal cavity. ${ }^{4}$ The maximal vagal stimulus was likely transient, as our patient returned to baseline after a brief near-syncopal episode.

As illustrated in our case, though tachycardia is common in splenic rupture, not all patients present with this sign. The absence of tachycardia in our patient can be explained by the elevation of his baseline enteric vagal tone due to the continued presence of blood in the peritoneum. ${ }^{5}$ There are also other factors associated with the absence of tachycardia. For example, a well-conditioned athlete presenting with states of shock due to splenic rupture may not show signs of tachycardia. ${ }^{6}$

\section{San Francisco Syncope Rule}

The San Francisco Syncope Rule (SFSR) is a clinical decision-making risk-stratification tool used to determine outcomes and disposition of ED patients presenting with syncope. ${ }^{7}$ It is important to note that if we had used a straightforward application of the SFSR upon our patient's initial presentation, the results would have been negative, suggesting he was not at risk for short-term serious outcomes. ${ }^{7}$

\section{Imaging Studies}

As demonstrated in our patient, a quick point-of-care (POC) bedside ultrasound scan can reveal the presence of free fluid in the abdomen to help with the diagnosis. On ultrasound, the presence of free fluid in the right upper quadrant is more commonly found in the hepatorenal recess, 
whereas in the left upper quadrant free fluid is seen sub-diaphragmatic/suprasplenic first before fluid is seen in the splenorenal recess. Bedside ultrasound can accurately detect as little as $100 \mathrm{~mL}$ of free fluid in the abdominal cavity, with a $90 \%$ sensitivity and $99 \%$ specificity. ${ }^{8}$

An ultrasound is highly sensitive as a preliminary screening tool to identify the presence of free intraperitoneal fluid and has some limited utility in identifying any disruption in the splenic echotexture that may suggest a laceration or hematoma. Ultrasound, however, has poor specificity in identifying solid organ injuries. ${ }^{9}$

Computed tomography scanning is the imaging modality of choice for assessing splenic injuries, and should be obtained to confirm the presence of a solid organ injury, as well as to grade the degree of injury and thereby determine the need for surgical intervention. ${ }^{10}$ It is worth noting that in a hemodynamically unstable patient, exploratory laparotomy may be embarked upon without a CT scan and positive free fluid on ultrasound.

\section{Splenic Injury Scale}

Splenic injury is classified on a scale of 1 (mild injury) to 5 (severe injury) (Table). ${ }^{11}$

\section{References}

1. Renzulli P, Hostettler A, Schoepfer AM, Gloor B, Candinas D. Systematic review of atraumatic splenic rupture. Br J Surg. 2009;96(10):1114-1121. doi: 10.1002/bjs.6737

2. Aubrey-Bassler FK, Sowers N. 613 cases of splenic rupture without risk factors or previously diagnosed disease: a systematic review. BMC Emerg Med. 2012;12:11. doi: 10.1186/1471-227X-12-11.

3. Schattner A, Meital A, Mavor E. Red-flag syncope: spontaneous splenic rupture. Am J Med. 2014;127(6):501502. doi: 10.1016/j.amjmed.2014.02.024.

4. Moya A, Sutton R, Ammirati F, et al; Task Force for the Diagnosis and Management of Syncope; European Society of Cardiology (ESC); European Heart Rhythm Association (EHRA); Heart Failure Association (HFA); Heart Rhythm Society (HRS). Guidelines for the diagnosis and management of syncope (version 2009). Eur Heart J. 2009;30(21):2631-2671. doi: 10.1093/eurheartj/ehp298.

5. Rana MS, Khalid U, Law S. Paradoxical bradycardia in a patient with haemorrhagic shock secondary to blunt abdominal trauma. BMJ Case Rep. 2010;2010. doi: 10.1136/bcr.04.2010.2872.

6. Kiss O, Sydó N, Vargha P, et al. Prevalence of physiological and pathological electrocardiographic
Nontraumatic splenic rupture is managed nonoperatively or surgically based on the grade of the injury as well as the patient's hemodynamic status. Grades 1 and 2 are managed mostly conservatively, whereas grades 4 and 5 are managed mostly operatively. ${ }^{12}$ A review of 845 cases from 1980 to 2008 found that $14.7 \%$ were treated conservatively. ${ }^{1}$ Due to the immunosuppressive effects of splenectomy, there has been a recent push toward conservative treatment. ${ }^{12}$

\section{Conclusion}

This case illustrates an uncommon presentation of NSR and underscores the importance of considering NSR in the differential diagnoses of patients presenting with abdominal pain-a sign with such a broad differential that NSR could easily be missed during evaluation. Based on its high sensitivity and specificity in detecting the presence of free fluid in the abdominal cavity, POC ultrasound imaging should be used to evaluate patients presenting with abdominal pain and syncopal or near-syncopal symptoms. This case further demonstrates that the absence of tachycardia or signs of shock should not rule out NSR.

findings in Hungarian athletes. Acta Physiol Hung. 2015;102(2):228-237. doi: 10.1556/036.102.2015.2.13.

7. Quinn JV, Stiell IG, McDermott DA, Sellers KL, Kohn MA, Wells GA. Derivation of the San Francisco Syncope Rule to predict patients with short-term serious outcomes. Ann Emerg Med. 2004;43(2):224-232.

8. Ma OJ, Mateer JR, Ogata M, Kefer MP, Wittmann D, Aprahamian C. Prospective analysis of a rapid trauma ultrasound examination performed by emergency physicians. J Trauma. 1995;38(6):879-885.

9. Kendall JL, Faragher J, Hewitt GJ, Burcham G Haukoos JS. Emergency Department Ultrasound Is not a Sensitive Detector of Solid Organ Injury. West $J$ Emerg Med. 2009;10(1):1-5.

10. Hassan R, Abd Aziz A, Md Ralib AR, Saat A. Computed tomography of blunt spleen injury: a pictorial review. Malays J Med Sci. 2011;18(1):60-67.

11. Moore EE, Cogbill TH, Jurkovich GJ, Shackford SR, Malangoni MA, Champion HR. Organ injury scaling: spleen and liver (1994 revision). J Trauma. 1995;38(3):323-324.

12. Cirocchi R, Boselli C, Corsi A, et al. Is nonoperative management safe and effective for all splenic blunt trauma? A systematic review. Crit Care. 2013;17(5):R185. doi: 10.1186/cc12868. 